\title{
Potential diabetes overtreatment and risk of adverse events among older adults in Ontario: a population-based study
}

\author{
Iliana C. Lega ${ }^{1,2,3}$ - Michael A. Campitelli ${ }^{3} \cdot$ Peter C. Austin ${ }^{3}(1) \cdot$ Yingbo $^{2} a^{1,3} \cdot$ Afshan Zahedi $^{1,2} \cdot$ Freda Leung $^{4}$. \\ Catherine $\mathrm{Yu}^{2,5}$. Susan E. Bronskill ${ }^{1,3} \cdot$ Paula A. Rochon ${ }^{1,3,6}$ (D) Lorraine L. Lipscombe ${ }^{1,2,3}$ (D)
}

Received: 10 August 2020 / Accepted: 5 November 2020 / Published online: 25 January 2021

(C) The Author(s), under exclusive licence to Springer-Verlag GmbH, DE part of Springer Nature 2021

\begin{abstract}
Aims/hypothesis More than $25 \%$ of older adults (age $\geq 75$ years) have diabetes and may be at risk of adverse events related to treatment. The aim of this study was to assess the prevalence of intensive glycaemic control in this group, potential overtreatment among older adults and the impact of overtreatment on the risk of serious events.

Methods We conducted a retrospective, population-based cohort study of community-dwelling older adults in Ontario using administrative data. Participants were $\geq 75$ years of age with diagnosed diabetes treated with at least one anti-hyperglycaemic agent between 2014 and 2015. Individuals were categorised as having intensive or conservative glycaemic control $\left(\mathrm{HbA}_{1 \mathrm{c}}\right.$ $<53 \mathrm{mmol} / \mathrm{mol}[<7 \%]$ or $54-69 \mathrm{mmol} / \mathrm{mol}$ [7.1-8.5\%], respectively), and as undergoing treatment with high-risk (i.e. insulin, sulfonylureas) or low-risk (other) agents. We measured the composite risk of emergency department visits, hospitalisations, or death within 30 days of reaching intensive glycaemic control with high-risk agents.

Results Among 108,620 older adults with diagnosed diabetes in Ontario, the mean $( \pm$ SD) age was $80.6( \pm 4.5)$ years, $49.7 \%$ were female, and mean $( \pm \mathrm{SD})$ diabetes duration was $13.7( \pm 6.3)$ years. Overall, $61 \%$ of individuals were treated to intensive glycaemic control and $21.6 \%$ were treated to intensive control using high-risk agents. Using inverse probability treatment weighting with propensity scores, intensive control with high-risk agents was associated with nearly $50 \%$ increased risk of the composite outcome compared with conservative glycaemic control with low-risk agents (RR 1.49, 95\% CI 1.08, 2.05).

Conclusions/interpretation Our findings underscore the need to re-evaluate glycaemic targets in older adults and to reconsider the use of anti-hyperglycaemic medications that may lead to hypoglycaemia, especially in setting of intensive glycaemic control.
\end{abstract}

Keywords Diabetes overtreatment $\cdot$ Healthcare delivery $\cdot$ Hypoglycaemia $\cdot$ Insulin secretagogues $\cdot$ Insulin therapy $\cdot$ Intensive glycaemic control $\cdot$ Older adults

Iliana C. Lega

iliana.lega@wchospital.ca

1 Women's College Research Institute, Women's College Hospital, Toronto, ON, Canada

2 Division of Endocrinology and Metabolism, Department of Medicine, University of Toronto, Toronto, ON, Canada

3 ICES, Toronto, ON, Canada

4 Scarborough and Rouge Hospital, Toronto, ON, Canada

5 Li Ka Shing Knowledge Institute, St Michael's Hospital, Toronto, ON, Canada

6 Division of Geriatric Medicine, Department of Medicine, University of Toronto, Toronto, ON, Canada

\section{Abbreviations}

ED Emergency department

IPTW Inverse probability of treatment weighting

\section{Introduction}

The prevalence of diabetes is highest in older age groups, with more than $25 \%$ of adults aged $\geq 75$ years affected by diabetes [1-3]. For most individuals, intensive glycaemic control (i.e. targeting $\mathrm{HbA}_{1 \mathrm{c}}$ to $<53 \mathrm{mmol} / \mathrm{mol}[7 \%]$ ) is recommended to reduce the risk of long-term microvascular complications [4-6]. However, achieving intensive control, especially with 


\section{Research in context}

\section{What is already known about this subject?}

- $\quad$ Older adults with type 2 diabetes are at high risk of hypoglycaemia, especially when treated to intensive glycaemic control with high-risk agents

- Although diabetes guidelines increasingly recommend relaxing glycaemic targets, there is evidence of overtreatment among older adults

- Ongoing efforts are needed to reduce the burden of diabetes overtreatment in older adults and to promote safe prescribing in this population

\section{What is the key question?}

- What is the risk of emergency room visits, hospitalisations or death among older adults who are treated to intensive glycaemic control $\left(\mathrm{HbA}_{1 \mathrm{c}}<53 \mathrm{mmol} / \mathrm{mol}[<7 \%]\right)$ with high-risk agents?

What are the new findings?

- Among 108,620 older adults with diagnosed diabetes in Ontario (mean [ \pm SD]) age $80.6( \pm 4.5)$ years, $61 \%$ were treated to intensive glycaemic control and $21.6 \%$ were treated to intensive control with high-risk agents

- Using inverse probability treatment weighting propensity scores, intensive control with high-risk agents was associated with a nearly $50 \%$ increased risk of the composite outcome compared with conservative glycaemic control with low-risk agents

\section{How might this impact on clinical practice in the foreseeable future?}

- An initiative to promote deintensification of diabetes medications, especially in the setting of intensive glycaemic control and high-risk agents, is critical for optimising the health of older adults with diabetes

insulin and/or sulfonylureas, increases the risk of hypoglycaemia [7]. The care of diabetes in older adults is complicated by multiple comorbidities and impaired counter-regulatory mechanisms, rendering older adults more vulnerable to hypoglycaemia than younger people [8, 9]. Hypoglycaemia is particularly dangerous in older individuals at high risk of cardiovascular events, falls, neurocognitive decline and increased mortality rate [10-15]. It may take up to a decade for the benefits of intensive control to be seen [16-18]; therefore, the short-term risks might outweigh the longer-term benefits in older populations.

Recent guidelines recommend more conservative glycaemic targets (i.e. $\mathrm{HbA}_{1 \mathrm{c}}$ 54-69 $\mathrm{mmol} / \mathrm{mol}$ [7.1$8.5 \%]$ ) in older adults $[19,20]$. However, there is evidence that this group continues to be treated to intensive glycaemic targets, and is potentially overtreated with agents that are associated with a high risk of hypoglycaemia (i.e. insulin and sulfonylurea) $[8,21,22]$. Treatment to intensive glycaemic targets using high-risk agents has been defined as diabetes overtreatment in older adults [4, 7, 8, 22, 23]. While previous studies have shown an increased risk of severe hypoglycaemia with intensive control [14, 24, 25], few have focused on the risk of high-risk agents in the setting of intensive glycaemic control. In addition, the risk of serious events associated with intensive glycaemic control with high-risk agents has not been evaluated at the population level. Our primary objectives were to: (1) describe the prevalence of intensive glycaemic control with high-risk agents and potential overtreatment among older adults with diabetes in Ontario; and (2) evaluate the impact of intensive control with high-risk agents on serious events.

\section{Methods}

Study design and setting We conducted a retrospective cohort study using linked, population-based health administrative databases for Ontario, Canada, held at ICES. These databases have been used extensively for the study of older adults with diabetes in Ontario [2, 26]. Datasets were linked using unique encoded identifiers and analysed at ICES. The use of data in this project was authorised under Section 45 of Ontario's Personal Health Information Protection Act, and did not require review by a research ethics board.

Participants We identified all Ontario residents aged $\geq 75$ years with diagnosed diabetes who had a prescription dispensed for at least one anti-hyperglycaemic agent between 1 September 2014 and 31 August 2015 (see Electronic supplementary material [ESM] Fig. 1). Diabetes was defined based on entry in the Ontario Diabetes Database (ESM Table 1), which is a validated database of individuals with diabetes [27]. Participants had to 
have been diagnosed with diabetes at least 1 year prior to index date to be included in the study. Study dates were chosen based on the most recently available data on $\mathrm{HbA}_{1 \mathrm{c}}$ levels in our Ontario Laboratories Information System datasets. The first available $\mathrm{HbA}_{1 \mathrm{c}}$ measurement during the study period was used as the index date. Outpatient prescription medication data were captured in the Ontario Drug Benefit database, which records prescription fills for all Ontarians aged $\geq 65$ years.

To be included in our study cohort, individuals needed at least one prescription for an anti-hyperglycaemic medication with a start date that overlapped with the index date $(+15$ day grace period) in order to ascertain current use of the antihyperglycaemic agent. Exclusion criteria are shown in ESM Fig. 1. We excluded individuals with $\mathrm{HbA}_{1 \mathrm{c}}>69 \mathrm{mmol} / \mathrm{mol}$ $(8.5 \%)$ because those with poorly controlled diabetes may be at higher risk of hospitalisation and mortality from factors unrelated to either their diabetes treatment or glycaemic control (e.g. poor adherence to medication and healthcare visits, competing demands from other comorbidities, social issues, end of life) [28].

Exposure and comparator groups We categorised individuals into four mutually exclusive exposure groups based on $\mathrm{HbA}_{1 \mathrm{c}}$ at the index date and current prescriptions for antihyperglycaemic agents. First, we defined glycaemic control as intensive $\left(\mathrm{HbA}_{1 \mathrm{c}}<53 \mathrm{mmol} / \mathrm{mol}[<7.0 \%]\right)$ or conservative $\left(\mathrm{HbA}_{1 \mathrm{c}}\right.$ 54-69 $\left.\mathrm{mmol} / \mathrm{mol}[7.1-8.5 \%]\right)$. We then subdivided each group into treatment with at least one high-risk agent (insulin and/or sulfonylurea) vs one or more low-risk agents only (metformin, dipeptidyl peptidase 4 inhibitor, acarbose, thiazolidinediones). Individuals in the high-risk group could be treated with concurrent low-risk anti-hyperglycaemic agents. The primary exposure of interest was intensive glycaemic control with high-risk anti-hyperglycaemic agents, representing potential overtreatment. The following mutually exclusive categories were used as the three comparator groups: conservative glycaemic control with low-risk agents (primary comparator), conservative glycaemic control with high-risk agents and intensive control with low-risk agents.

Outcomes Our primary outcome was a composite measure defined as a diabetes-related (including hypoglycaemia) emergency department (ED) visit or hospitalisation or all-cause mortality within 30 days of the index date. For ED visits and hospitalisations, we used diagnosis codes for: (1) hypoglycaemia, listed as the main responsible diagnosis for the visit; and (2) any other diabetes-related cause (e.g. hyperglycaemia, hypoglycaemia, ketoacidosis, hyperosmolar coma) (ESM Table 2). For all-cause mortality, we used the Ontario Registered Persons Database as the source of vital statistical records to determine death. We examined each outcome from the composite separately in secondary analyses.
Covariates Demographic covariates included age, sex, region of residence (rural vs urban) and income quintile (based on postal code). This information was derived from the Ontario Registered Persons Database. We used the Johns Hopkins' Aggregated Diagnosis Groups case-mix system (version 10.0) to compute the number of Aggregated Diagnosis Groups in the past 2 years as a general measure of comorbidity [29]. In addition, individual comorbidities were ascertained using ICD-10 codes from physician billing claims in the Ontario Health Insurance Plan database. Where available, we used validated ICES-derived cohorts or registries to capture individual comorbidities (i.e. history of cancer [30], dementia [31], congestive heart failure [32], coronary artery disease [33], atrial fibrillation [34], cerebrovascular disease [35]) (ESM Table 1). Diabetes complications (i.e. amputations, chronic renal failure/dialysis, skin/soft-tissue infections, retinopathy and previous diabetes mellitus-related healthcare contacts) and use of diabetes medications available on the formulary within 1 year of the index date were ascertained. As diabetes medications were captured up to 1 year prior to the index date, baseline diabetes medication use could represent either current or past use. We also captured the most recent serum creatinine, haemoglobin and $\mathrm{HbA}_{1 \mathrm{c}}$ values prior to the index date, based on available Ontario Laboratories Information System data. Baseline data were expressed as means $( \pm \mathrm{SD})$ where appropriate.

Statistical analyses We used inverse probability of treatment weighting (IPTW) using propensity scores to account for baseline differences among exposure groups. The advantage of propensity score methods is that, unlike conventional regression adjustment, no outcome regression model must be specified. Furthermore, it is possible to explicitly assess the degree to which weighting removes systematic baseline differences among groups [36]. We chose to use IPTW, in part, because the number of individuals with intensive control with high-risk agents $(n=23,484)$ was higher than in one of the comparator groups $(n=16,488)$, but smaller than in the other two comparator groups $(n=42,857$ and $n=25,791)$. Propensity score matching, in general, requires that the number of exposed participants is smaller than the number of potential control participants in each comparator group. To account for selection biases resulting from systematic differences in baseline characteristics among exposure groups, a propensity score was derived from all available baseline covariates using a multivariable logistic regression to determine the propensity for intensive glycaemic control with highrisk agents vs other comparator categories (ESM Table 3). A separate propensity score was derived for each pair of exposure and comparator groups. Given that $\mathrm{HbA}_{1 \mathrm{c}}$ and insulin and sulfonylurea use were part of the definition for the exposure group, these variables were not included in the logistic regression model used to calculate the propensity score. We 
then derived the IPTW and performed a weighted univariate analysis. A robust variance estimator that corrected for dependence among the weighted observations was used [36, 37]. Weighted standardised differences were calculated comparing the distribution of baseline covariates among treatment groups before and after weighting [37].

We evaluated the risk of the composite outcome associated with intensive glycaemic control with a high-risk agent within 30 days of the index date using a log-binomial model, weighted for inverse probability treatment of the propensity score. We performed three sets of unweighted and weighted analyses to compare events between the intensive control high-risk agent group and each of the three comparator groups separately.

Secondary analyses Assessment of the primary outcome was repeated with the follow-up period extended to 90 days to assess the longer-term risks associated with intensive glycaemic control with high-risk agents. We also evaluated the separate risks of: (1) hypoglycaemia-related ED visits/ hospitalisations; (2) diabetes-related ED visits/ hospitalisations (excluding hypoglycaemia); and (3) allcause mortality, using log-binomial models with IPTW using the comparison-specific propensity scores.

In order to isolate the effect of intensive glycaemic control with high-risk agents on the primary outcome, we also compared the difference in the risk of the primary outcome among individuals treated to intensive control with high- vs low-risk agents.

To account for the risk associated with persistent intensive control with high-risk agents on diabetes-related ED visit/ hospitalisations, we identified individuals who had intensive control with high-risk agents based on two consecutive $\mathrm{HbA}_{1 \mathrm{c}}$ values in the study period. We then compared the risk of diabetes-related $\mathrm{ED}$ visits/hospitalisations within 30 days between the first and second $\mathrm{HbA}_{1 \mathrm{c}}$ value.

Analyses were performed using SAS statistical software, version 9.4 (SAS Institute, Cary, NC, USA).

\section{Results}

Baseline data We identified 313,575 community-dwelling adults aged $\geq 75$ years with diagnosed diabetes in Ontario. After applying our exclusion criteria, 108,620 people were included in the study (ESM Fig. 1). Among these individuals, $66,341(61.1 \%)$ had intensive glycaemic control and 42,279 (38.9\%) had conservative glycaemic control based on the first available $\mathrm{HbA}_{1 \mathrm{c}}$. Overall, 23,484 (21.6\%) had intensive control with high-risk agents; and 42,857 (39.5\%) had intensive control with low-risk agents. There were 25,791 (23.7\%) individuals with conservative glycaemic control on high-risk agents and 16,488 (15.2\%) with conservative control on lowrisk agents (Table 1). The baseline characteristics were well balanced after weighting for each pair of exposure and comparator groups, with standardised differences among variables after weighting remaining below 0.1 . After weighting, the maximum standardised differences were 0.092 (for the exposure group vs conservative glycaemic control with lowrisk agents), 0.064 (for exposure vs conservative glycaemic control with high-risk agents) and 0.059 (for exposure vs intensive glycaemic control with high-risk agents) (ESM Table 4).

Primary analysis Figure 1 shows the crude cumulative incidence of the composite outcome in the 90 days following the index $\mathrm{HbA}_{1 \mathrm{c}}$ measurement for each group. Among those with intensive control with high-risk agents, 217 individuals $(0.92 \%)$ experienced the primary outcome at 30 days, compared with $68(0.41 \%)$ among those with conservative glycaemic control with low-risk agents, $174(0.67 \%)$ among those with conservative glycaemic control with high-risk agents and $178(0.42 \%)$ among those with intensive control with low-risk agents (Fig. 1). In unweighted results, intensive control with high-risk agents was associated with a 2.24-fold increased risk of the composite outcome compared with individuals with conservative glycaemic control with low-risk agents (RR 2.24, 95\% CI 1.74, 2.94) (Table 2). In propensity score weighted analyses, there was a nearly $50 \%$ increased risk of the composite outcome among individuals with intensive glycaemic control with high-risk agents vs conservative glycaemic control with low-risk agents (RR 1.49, 95\% CI $1.08,2.05$ ) (Table 2). In weighted analyses, the risk associated with intensive control with high-risk agents was also significantly increased compared with conservative glycaemic control with high-risk agents (RR 1.25, 95\% CI 1.02, 1.52) and intensive glycaemic control with low-risk agents (RR $1.48,95 \%$ CI 1.18, 1.85) (Table 2).

Secondary analyses When the follow-up window was extended to 90 days, those with intensive glycaemic control with high-risk agents had a $27 \%$ increased risk (RR $1.27,95 \%$ CI $1.07,1.51)$ of the composite outcome compared with individuals with conservative glycaemic control with low-risk agents (Table 2). The risk of the composite outcome remained increased vs individuals with intensive control with low-risk agents, but there was no difference in outcomes for individuals on high-risk agents with either intensive or conservative glycaemic control (Table 2).

Compared with individuals with conservative glycaemic control with low-risk agents, those with intensive glycaemic control with high-risk agents had a greater than sixfold increased risk of a hypoglycaemia-related ED visit/ hospitalisation (RR 6.83, 95\% CI 2.89, 16.2), a nearly twofold increased risk of a diabetes-related (excluding hypoglycaemia) ED visit/hospitalisation (RR 1.94, 95\% CI $1.06,3.57)$ and no increased risk of all-cause mortality (RR 
Table 1 Baseline characteristics of older adults in Ontario treated for diabetes with an $\mathrm{HbA}_{1 \mathrm{c}}$ of $\leq 69 \mathrm{mmol} / \mathrm{mol}(\leq 8.5 \%)$

\begin{tabular}{|c|c|c|c|c|c|}
\hline \multirow[t]{2}{*}{ Characteristic } & \multirow[t]{2}{*}{ Overall population } & \multicolumn{2}{|c|}{$\begin{array}{l}\text { Intensive glycaemic control }\left(\mathrm{HbA}_{1 \mathrm{c}}\right. \\
\leq 53 \mathrm{mmol} / \mathrm{mol}[\leq 7.0 \%])\end{array}$} & \multicolumn{2}{|c|}{$\begin{array}{l}\text { Conservative glycaemic control }\left(\mathrm{HbA}_{1 \mathrm{c}}\right. \\
54-69 \mathrm{mmol} / \mathrm{mol}[7.1-8.5 \%])\end{array}$} \\
\hline & & High-risk agents ${ }^{\mathrm{a}}$ & Low-risk agents ${ }^{\mathrm{a}}$ & High-risk agents ${ }^{\mathrm{a}}$ & Low-risk agents $^{\mathrm{a}}$ \\
\hline$n$ & 108,620 & 23,484 & 42,857 & 25,791 & 16,488 \\
\hline Age, years & $80.63 \pm 4.53$ & $80.73 \pm 4.56$ & $80.67 \pm 4.54$ & $80.44 \pm 4.43$ & $80.66 \pm 4.61$ \\
\hline \multicolumn{6}{|l|}{ Age category } \\
\hline 75-79 years & $52,281(48.1)$ & $11,124(47.4)$ & $20,441(47.7)$ & $12,823(49.7)$ & $7893(47.9)$ \\
\hline 80-84 years & $34,934(32.2)$ & $7511(32.0)$ & $13,852(32.3)$ & $8254(32.0)$ & $5317(32.2)$ \\
\hline$>85$ years & $21,405(19.7)$ & 4849 (20.6) & $8564(20.0)$ & $4714(18.3)$ & $3278(19.9)$ \\
\hline Female & $54,015(49.7)$ & $10,817(46.1)$ & $22,183(51.8)$ & $12,679(49.2)$ & $8336(50.6)$ \\
\hline \multicolumn{6}{|l|}{ Income quintile } \\
\hline 1 & $26,237(24.2)$ & $5838(24.9)$ & $10,234(23.9)$ & $6319(24.5)$ & $3846(23.3)$ \\
\hline 2 & $25,740(23.7)$ & $5611(23.9)$ & $10,144(23.7)$ & $6053(23.5)$ & $3932(23.9)$ \\
\hline 3 & 21,469 (19.8) & 4609 (19.7) & $8474(19.8)$ & $5160(20.0)$ & $3226(19.6)$ \\
\hline 4 & $18,287(16.9)$ & $3938(16.8)$ & 7149 (16.7) & $4416(17.1)$ & $2784(16.9)$ \\
\hline 5 & $16,767(15.5)$ & $3453(14.7)$ & $6800(15.9)$ & 3825 (14.8) & $2689(16.3)$ \\
\hline Urban region of residence & $96,743(89.2)$ & $20,921(89.2)$ & $38,514(90.0)$ & $22,639(87.8)$ & $14,669(89.0)$ \\
\hline Baseline $\mathrm{HbA}_{1 \mathrm{c}}, \mathrm{mmol} / \mathrm{mol}(\%)$ & $\begin{array}{l}52.2 \pm 9.4 \\
\quad(6.93 \pm 0.86)\end{array}$ & $\begin{array}{l}49.5 \pm 8.20 \\
\quad(6.68 \pm 0.75)\end{array}$ & $\begin{array}{l}47.1 \pm 6.10 \\
\quad(6.46 \pm 0.56)\end{array}$ & $\begin{array}{l}60.1 \pm 9.20 \\
\quad(7.65 \pm 0.84)\end{array}$ & $\begin{array}{l}56.8 \pm 7.80 \\
\quad(7.35 \pm 0.71)\end{array}$ \\
\hline Baseline haemoglobin, g/l & $127.90 \pm 15.43$ & $125.84 \pm 16.08$ & $129.08 \pm 15.26$ & $126.97 \pm 15.13$ & $129.25 \pm 14.95$ \\
\hline Serum creatinine, $\mu \mathrm{mol} / \mathrm{ml}$ & $98.53 \pm 51.15$ & $111.44 \pm 71.23$ & $90.77 \pm 35.83$ & $104.74 \pm 55.96$ & $90.55 \pm 35.27$ \\
\hline Diabetes duration, years & $13.7 \pm 6.28$ & $15.53 \pm 5.97$ & $11.18 \pm 5.76$ & $16.89 \pm 5.61$ & $12.94 \pm 5.98$ \\
\hline \multicolumn{6}{|c|}{ Diabetes medication (within 1 year of index date) } \\
\hline Metformin & $89,000(81.9)$ & $15,475(65.9)$ & $40,309(94.1)$ & $17,774(68.9)$ & $15,442(93.7)$ \\
\hline Sulfonylurea & $39,777(36.6)$ & $18,379(78.3)$ & $1615(3.8)$ & $17,902(69.4)$ & $1881(11.4)$ \\
\hline DPP4 inhibitor & $24,690(22.7)$ & $5332(22.7)$ & $7087(16.5)$ & $7803(30.3)$ & $4468(27.1)$ \\
\hline Insulin & $20,169(18.6)$ & $6487(27.6)$ & $818(1.9)$ & $11,245(43.6)$ & $1619(9.8)$ \\
\hline TZD & $1772(1.6)$ & $539(2.3)$ & $525(1.2)$ & $502(1.9)$ & $206(1.2)$ \\
\hline Acarbose & $1426(1.3)$ & $380(1.6)$ & $269(0.6)$ & $617(2.4)$ & $160(1.0)$ \\
\hline Glitinide & $336(0.3)$ & $20(0.1)$ & $140(0.3)$ & $46(0.2)$ & $130(0.8)$ \\
\hline No diabetes medication & $378(0.3)$ & $31(0.1)$ & $309(0.7)$ & $6(0.0)$ & $32(0.2)$ \\
\hline $\begin{array}{l}\text { Unique diabetes medication (1 year } \\
\text { prior) }\end{array}$ & $2(1-2)$ & $2(2-3)$ & $1(1-1)$ & $2(2-3)$ & $1(1-2)$ \\
\hline \multicolumn{6}{|l|}{ Diabetes complications } \\
\hline Amputation & $405(0.4)$ & $117(0.5)$ & $96(0.2)$ & $137(0.5)$ & $55(0.3)$ \\
\hline $\mathrm{CKD}$ & $19,250(17.7)$ & $5976(25.4)$ & $5276(12.3)$ & $5992(23.2)$ & $2006(12.2)$ \\
\hline Dialysis & $453(0.4)$ & $249(1.1)$ & $45(0.1)$ & $143(0.6)$ & $16(0.1)$ \\
\hline Skin/soft-tissue infection & $1822(1.7)$ & $567(2.4)$ & $520(1.2)$ & $528(2.0)$ & $207(1.3)$ \\
\hline Treatment for retinopathy & $4676(4.3)$ & $1181(5.0)$ & $1095(2.6)$ & $1802(7.0)$ & $598(3.6)$ \\
\hline $\begin{array}{l}\text { ED/hospitalisation for } \\
\text { hyperglycaemia-related cause }\end{array}$ & $462(0.4)$ & $120(0.5)$ & $73(0.2)$ & $214(0.8)$ & $55(0.3)$ \\
\hline $\begin{array}{l}\text { ED/hospitalisation for } \\
\text { hypoglycaemia-related cause }\end{array}$ & $2572(2.4)$ & $874(3.7)$ & $421(1.0)$ & $1013(3.9)$ & $264(1.6)$ \\
\hline $\begin{array}{l}\text { ED/hospitalisation for diabetes-related } \\
\text { cause }\end{array}$ & $7246(6.7)$ & $2132(9.1)$ & $1573(3.7)$ & $2716(10.5)$ & $825(5.0)$ \\
\hline \multicolumn{6}{|l|}{ Other comorbidity } \\
\hline Dementia & $9014(8.3)$ & $2018(8.6)$ & $3635(8.5)$ & $2016(7.8)$ & $1345(8.2)$ \\
\hline $\mathrm{CHF}$ & $19,640(18.1)$ & $5137(21.9)$ & $6340(14.8)$ & $5557(21.5)$ & $2606(15.8)$ \\
\hline History of $\mathrm{PCI} / \mathrm{CABG} / \mathrm{MI} / \mathrm{AF}$ & $36,879(34.0)$ & $8452(36.0)$ & $13,537(31.6)$ & $9431(36.6)$ & $5459(33.1)$ \\
\hline Cerebrovascular disease & $1984(1.8)$ & $447(1.9)$ & $739(1.7)$ & $498(1.9)$ & $300(1.8)$ \\
\hline
\end{tabular}

ADG score 
Table 1 (continued)

\begin{tabular}{|c|c|c|c|c|c|}
\hline \multirow[t]{2}{*}{ Characteristic } & \multirow[t]{2}{*}{ Overall population } & \multicolumn{2}{|c|}{$\begin{array}{l}\text { Intensive glycaemic control }\left(\mathrm{HbA}_{1 \mathrm{c}}\right. \\
\leq 53 \mathrm{mmol} / \mathrm{mol}[\leq 7.0 \%])\end{array}$} & \multicolumn{2}{|c|}{$\begin{array}{l}\text { Conservative glycaemic control }\left(\mathrm{HbA}_{1 \mathrm{c}}\right. \\
54-69 \mathrm{mmol} / \mathrm{mol}[7.1-8.5 \%])\end{array}$} \\
\hline & & High-risk agents ${ }^{\mathrm{a}}$ & Low-risk agents ${ }^{\mathrm{a}}$ & High-risk agents ${ }^{\mathrm{a}}$ & Low-risk agents $^{\mathrm{a}}$ \\
\hline Mean \pm SD & $11.42 \pm 4.04$ & $11.67 \pm 4.08$ & $11.31 \pm 4.02$ & $11.55 \pm 4.05$ & $11.18 \pm 4.04$ \\
\hline Median (IQR) & $11(9-14)$ & $12(9-15)$ & $11(8-14)$ & $12(9-14)$ & $11(8-14)$ \\
\hline \multicolumn{6}{|l|}{ Provider type } \\
\hline Internal medicine & $33,284(30.6)$ & $8061(34.3)$ & $11,805(27.5)$ & $8776(34.0)$ & $4642(28.2)$ \\
\hline Endocrinology & $13,862(12.8)$ & $3521(15.0)$ & $2959(6.9)$ & $5731(22.2)$ & $1651(10.0)$ \\
\hline Family medicine & $97,619(89.9)$ & $20,962(89.3)$ & 39,167 (91.4) & $22,408(86.9)$ & $15,082(91.5)$ \\
\hline Other & $5044(4.6)$ & $1269(5.4)$ & $1603(3.7)$ & $1452(5.6)$ & $720(4.4)$ \\
\hline Unknown & $8048(7.4)$ & $1938(8.3)$ & $2397(5.6)$ & $2500(9.7)$ & $1213(7.4)$ \\
\hline
\end{tabular}

Data are $n(\%)$, mean $\pm \mathrm{SD}$ or median (IQR)

High-risk agents were insulin and sulfonylureas; low-risk agents were metformin, DPP4 inhibitors, TZDs, acarbose and glitinides

ADG, Aggregated Diagnosis Group; AF, atrial fibrillation; CABG, coronary artery bypass graft; CHF, congestive heart failure; CKD, chronic kidney disease; DPP4; dipeptidyl peptidase 4; MI, myocardial infarction; PCI, percutaneous coronary intervention; TZD, thiazolidinedione

$1.05,95 \%$ CI $0.70,1.57)$ after 30 days. Results comparing outcomes among different comparator groups are summarised in Table 3.

There was no difference in the risk of the primary outcome among individuals treated with low-risk agents when comparing those with intensive vs conservative glycaemic control (RR 1.04, 95\% CI 0.77, 1.39) (results not shown).

Among those with intensive glycaemic control with highrisk agents, 12,475 (53.1\%) individuals were persistently treated to intensive control with high-risk agents based on the subsequent $\mathrm{HbA}_{1 \mathrm{c}}$ in the study period. This was associated with a $15 \%$ increased risk of a diabetes-related ED visit/ hospitalisation compared with having only one episode of intensive glycaemic control with high-risk agents (RR 1.15, 95\% CI 1.05, 1.26) (results not shown).

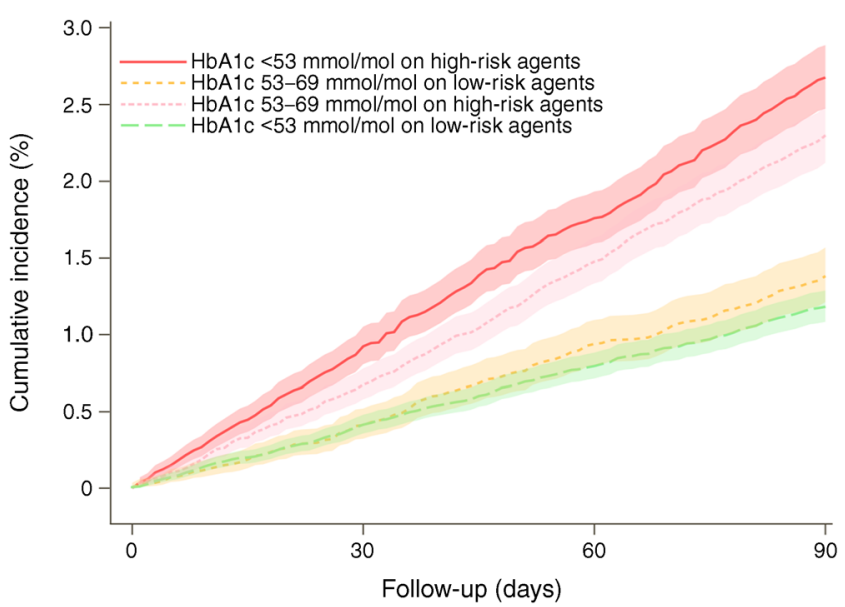

Fig. 1 Crude cumulative incidence of the composite of diabetes-related ED visit/hospitalisation or all-cause death over 90 days among older adults with diabetes. The shaded regions indicate the upper and lower $95 \%$ CI

\section{Discussion}

In this large population-based study of more than 100,000 community-dwelling older adults (age $\geq 75$ years) with diabetes treated with pharmacotherapy and an $\mathrm{HbA}_{1 \mathrm{c}}$ of $\leq 69 \mathrm{mmol} /$ mol $(\leq 8.5 \%), 61.1 \%$ were treated to intensive glycaemic targets and, overall, $21.6 \%$ were treated to intensive glycaemic targets with agents associated with a high risk of hypoglycaemia. Intensive glycaemic control with high-risk agents was associated with a significantly increased risk of our composite outcome of diabetes-related hospital visits and/or death compared with more conservative glycaemic control, regardless of the type of anti-hyperglycaemic medication. Among individuals treated with intensive control, the risk of serious adverse events was significantly higher with high- vs low-risk agents, indicating that the dangers of intensive control may be driven primarily by the use of high-risk agents for hypoglycaemia. Our study is the first to examine the combined influence of intensive glycaemic targets and highrisk agents on adverse outcomes in adults over the age of 75 years.

Our study provides evidence of potential diabetes overtreatment in a substantial proportion of individuals aged $\geq 75$ years, with nearly $1 \%$ experiencing a serious adverse event, including death, within 30 days. It adds to the growing body of evidence demonstrating harm with intensive glycaemic control and highlights the risk of adverse events with high-risk agents in older adults. Previous clinical trials reported an increased risk of severe hypoglycaemia with intensive glycaemic control, and even mortality risk [5, 6, 15, 38]. However, these were primarily controlled clinical trials where participants are younger and generally healthier than in the real world [39], and the effects of treatment 
Table 2 Impact of intensive glycaemic control with high-risk agents on risk of diabetes-related ED visit/hospitalisation or all-cause mortality

\begin{tabular}{|c|c|c|c|}
\hline Comparator groups & Events, $n(\%)$ & Univariate RR (95\% CI) & Weighted $\mathrm{RR}^{\mathrm{a}}(95 \% \mathrm{CI})$ \\
\hline \multicolumn{4}{|l|}{30 days } \\
\hline Intensive control, high-risk agents vs & $217(0.92)$ & $2.24(1.71,2.94)$ & $1.49(1.08,2.05)$ \\
\hline Conservative control, low-risk agents & $68(0.41)$ & Ref. & Ref. \\
\hline Intensive control, high-risk agents vs & $217(0.92)$ & $1.37(1.12,1.67)$ & $1.25(1.02,1.52)$ \\
\hline Conservative control, high-risk agents & $174(0.67)$ & Ref. & Ref. \\
\hline Intensive control, high-risk agents vs & $217(0.92)$ & $2.22(1.82,2.71)$ & $1.48(1.18,1.85)$ \\
\hline Intensive control, low-risk agents & $178(0.42)$ & Ref. & Ref. \\
\hline \multicolumn{4}{|l|}{90 days } \\
\hline Intensive control, high-risk agents vs & $628(2.67)$ & $1.93(1.66,2.25)$ & $1.27(1.07,1.51)$ \\
\hline Conservative control, low-risk agents & $228(1.38)$ & Ref. & Ref. \\
\hline Intensive control, high-risk agents vs & $628(2.67)$ & $1.16(1.04,1.30)$ & $1.07(0.95,1.19)$ \\
\hline Conservative control, high-risk agents & $592(2.30)$ & Ref. & Ref. \\
\hline Intensive control, high-risk agents vs & $628(2.67)$ & $2.26(2.01,2.54)$ & $1.55(1.36,1.77)$ \\
\hline Intensive control, low-risk agents & $507(1.18)$ & Ref. & Ref. \\
\hline
\end{tabular}

High-risk agents were insulin and sulfonylureas; low-risk agents were metformin, dipeptidyl peptidase 4 inhibitors, thiazolidinediones, acarbose and glitinides

${ }^{a}$ Model weighted by inverse probability of being overtreated based on propensity score of baseline variables

regimens were not isolated. More recently, a study using data from the National Health and Nutrition Examination Survey reported an attributable excess risk of hypoglycaemia-related ED visits or hospitalisations with an $\mathrm{HbA}_{1 \mathrm{c}}$ of $<38 \mathrm{mmol} / \mathrm{mol}$ $(<5.6 \%)$, regardless of the anti-hyperglycaemic agents used [25]. However, this study did not evaluate the excess risk in older adults, who are the most vulnerable, nor did it isolate the risk associated with high-risk medications. Another US study reported that intensive control among older adults was associated with a $77 \%$ increased risk of severe hypoglycaemia, even when excluding individuals on insulin who would be expected to have the highest risk of hypoglycaemia [24]. We report that adults taking insulin or sulfonylurea, especially with intensive control, had a higher risk of serious events compared with those on low-risk agents.
Insulin and sulfonylureas are two of the top four drugs associated with serious drug-related events among older adults [7], and our findings underscore the dangers of intensive control particularly among individuals using these highrisk agents. While the use of insulin may be appropriate in older adults in certain settings (e.g. reduced renal function, loss of secretory insulin capacity), clinicians need to use it with caution and aim for higher glycaemic targets in these settings. Similarly, because longer-acting sulfonylureas (e.g. glibenclamide [known as glyburide in the USA and Canada], chlorpropamide) may further increase the risk of hypoglycaemia, the use of these agents should be avoided [40]. Assessing frailty in older adults is also critical when choosing glycaemic targets. Frailty is associated with decreased life expectancy and is a better predictor of mortality

Table 3 Impact of intensive glycaemic control with high-risk agents vs comparators (conservative control, low/high-risk agents; intensive control, lowrisk agents) on the risk of hypoglycaemia- or diabetes-related ED visit/hospitalisation and all-cause mortality at 30 days

\begin{tabular}{|c|c|c|c|c|c|c|}
\hline \multirow[t]{2}{*}{ Comparator } & \multicolumn{2}{|c|}{$\begin{array}{l}\text { Hypoglycaemia-related ED visit/ } \\
\text { hospitalisation }\end{array}$} & \multicolumn{2}{|c|}{$\begin{array}{l}\text { Diabetes-related ED visit/ } \\
\text { hospitalisation }\end{array}$} & \multicolumn{2}{|c|}{ All-cause mortality } \\
\hline & Univariate & Weighted $^{\mathrm{a}}$ & Univariate & Weighted $^{\mathrm{a}}$ & Univariate & Weighted $^{\mathrm{a}}$ \\
\hline Conservative control, low-risk agents & $8.07(3.15,18.6)$ & $6.83(2.89,16.2)$ & $2.65(1.58,4.46)$ & $1.94(1.06,3.57)$ & $1.61(1.15,2.27)$ & $1.05(0.70,1.57)$ \\
\hline Conservative control, high-risk agents & $1.68(1.16,2.45)$ & $1.57(1.07,2.29)$ & $1.33(0.94,1.90)$ & $1.25(0.88,1.79)$ & $1.41(1.06,1.88)$ & $1.24(0.93,1.65)$ \\
\hline Intensive control, low-risk agents & $7.00(4.16,11.8)$ & $3.78(2.13,6.71)$ & $2.82(1.93,4.12)$ & $1.59(1.04,2.44)$ & $1.59(1.23,2.06)$ & $1.17(0.87,1.57)$ \\
\hline
\end{tabular}

Data are RR $(95 \% \mathrm{CI})$

High-risk agents were insulin and sulfonylureas; low-risk agents were metformin, dipeptidyl peptidase 4 inhibitors, thiazolidinediones, acarbose and glitinides

${ }^{a}$ Model weighted by the inverse probability of being overtreated based on the propensity score of baseline variables 
risk and adverse events than age or number of comorbidities $[19,41]$. As such, intensive glycaemic targets and high-risk agents should be particularly avoided in frail, older adults. Future studies that assess the impact of frailty on adverse outcomes with intensive glycaemic control are warranted.

The prevalence of intensive glycaemic control and potential overtreatment in our cohort is consistent with that reported in other studies. Several US studies have reported intensive control and overtreatment rates ranging from $26 \%$ to $54.9 \%$ in adults $>65$ years $[8,21,22]$. Similarly, a large European study reported that $44.7 \%$ of individuals aged $>65$ years identified from primary care registries were potentially overtreated [23]. Of concern is that the prevalence of overtreatment is similar among individuals who are frail or have multiple comorbidities, despite these groups being at the highest risk of hypoglycaemia and least likely to benefit from intensive glycaemic targets $[8,42]$. In our cohort, the high prevalence of intensive glycaemic control and potential overtreatment was similarly worrisome, since the mean age was 80 years and individuals had a high burden of comorbidities.

National and international diabetes guidelines are increasingly recommending higher glycaemic targets for older adults, especially for those with comorbidities and frailty. The ADA recommends an $\mathrm{HbA}_{1 \mathrm{c}}$ target of $<58 \mathrm{mmol} / \mathrm{mol}(<7.5 \%)$ for healthy older adults $(>65$ years) and $<64-69 \mathrm{mmol} / \mathrm{mol}(<8-$ $8.5 \%$ ) for older adults with multiple comorbidities, cognitive impairment or functional impairment [43]. Similarly, Diabetes Canada guidelines from 2013, which would have been contemporary to this study, recommended careful use of insulin and sulfonylureas in older adults and relaxing glycaemic targets to $\leq 69 \mathrm{mmol} / \mathrm{mol}(\leq 8.5 \%)$ in frail, older adults with multiple comorbidities [44]. More recently, the 2018 Diabetes Canada guidelines recommend that $\mathrm{HbA}_{1 \mathrm{c}}$ targets be no lower than $53 \mathrm{mmol} / \mathrm{mol}(7 \%)$ for older adults with frailty to account for the potential harms of intensive control [19]. Strategies for improving the dissemination and implementation of practice guidelines, such as communications campaigns, clinician and patient education, decision-support tools, audits and feedback are critical for aligning diabetes practice with recommendations for this vulnerable population $[45,46]$.

Clinical inertia once a treatment is started as well as a focus on standard glycaemic targets without adopting a personalised approach to treatment goals may be contributing to these trends [47]. We showed that the $\mathrm{HbA}_{1 \mathrm{c}}$ remained under $53 \mathrm{mmol} / \mathrm{mol}(7 \%)$ by the second $\mathrm{HbA}_{1 \mathrm{c}}$ test in over half of individuals with intensive control on a high-risk agent. Barriers for deintensifying glycaemic control in older adults may be a lack of evidence-based guidelines for deintensification [47], misperceptions as to possible negative repercussions of deprescribing and an underestimation of the potential harms [48]. A shared decision-making process between physician and patient, patient decision aids [6], patient-specific education on both the risks and benefits of treatment, and an understanding of each individual patient's values and preferences $[18,49]$ are critical for successful deprescribing strategies.

Strengths and limitations There are numerous strengths to our study. This is the first study, to our knowledge, that has evaluated the risk of serious adverse events associated with diabetes overtreatment on a population level in older adults. We used validated data sources and included a large populationbased, real-world sample of individuals with complete drug and laboratory data. We performed several comparisons and sensitivity analyses to support the robustness of our findings, and we used a propensity-weighted approach to account for baseline comorbidities and to minimise selection bias. However, there are limitations to this study. First, we based the category of glycaemic control on a single $\mathrm{HbA}_{1 \mathrm{c}}$ value, which may not be representative of ongoing glycaemic control. To address this, we performed a secondary analysis to account for ongoing overtreatment and found a similarly increased risk of ED visits/hospitalisations with persistent overtreatment. Second, while our analysis was propensityweight adjusted to account for all available baseline covariates, as in all observational studies, biases may have remained from unmeasured and unknown confounders. While propensity score methods can mitigate bias from confounding due to measured covariates, such methods are unable to account for confounding due to unmeasured confounders (both known and unknown unmeasured confounders). Nevertheless, in subgroup analyses of the individual outcomes, we found that after weighting there was no increased risk of mortality between our exposure and comparator groups, which suggests that we were able to account for important potential biases. Third, we only accounted for severe hypoglycaemia and diabetes-related events that resulted in ED visits, hospitalisations or death, and we may therefore be underreporting the true burden of serious events associated with intensive glycaemic control and high-risk agents.

Conclusions Using large representative provincial databases, we showed that a high proportion of community-dwelling older adults with diabetes are treated to intensive glycaemic targets, with one in five of these individuals exposed to potentially harmful medications. We report a nearly $50 \%$ increased shortterm risk of diabetes-related hospital visits or death associated with intensive glycaemic control with insulin or sulfonylureas, indicating the harms outweigh the benefits for these individuals. Our findings underscore recommendations from national diabetes guidelines that emphasise the risks associated with intensive control and overtreatment, especially among older adults.

Supplementary Information The online version of this article (https:// doi.org/10.1007/s00125-020-05370-7) contains peer-reviewed but unedited supplementary material. 
Acknowledgements Parts of this material are based on data and/or information compiled and provided by the Canadian Institute for Health Information (CIHI). However, the analyses, conclusions, opinions and statements expressed in the material are those of the authors, and not necessarily those of CIHI. In addition, we thank IMS Brogan Inc. for use of their Drug Information Database.

The authors wish to acknowledge the assistance of Vaidehi Misra (Women's College Research Institute, Toronto, ON, Canada) for her assistance with editing and formatting the manuscript.

Data availability The dataset from this study is held securely in coded form at ICES. While data sharing agreements prohibit ICES from making the dataset publicly available, access may be granted to those who meet pre-specified criteria for confidential access, available at www.ices.on.ca/ DAS. The full dataset creation plan and underlying analytic code are available from the authors upon request, understanding that the computer programs may rely upon coding templates or macros that are unique to ICES and are therefore either inaccessible or may require modification

Funding This study was supported by a grant from the Canadian Institutes of Health Research (CIHR) (1018890). LLL is supported by a Diabetes Investigator Award from Diabetes Canada. PCA is supported by a Mid-Career Investigator Award from the Heart and Stroke Foundation. PAR holds the RTO/ERO Chair in Geriatric Medicine from the University of Toronto. This study was supported by ICES, which is funded by an annual grant from the Ontario Ministry of Health and Long-Term Care (MOHLTC). ICES is an independent, non-profit research institute, the legal status of which under Ontario's health information privacy law allows it to collect and analyse healthcare and demographic data, without consent, for health system evaluation and improvement. The opinions, results and conclusions reported in this paper are those of the authors and are independent from the funding sources. No endorsement by ICES or the Ontario MOHLTC is intended or should be inferred.

Authors' relationships and activities The authors declare that there are no relationships or activities that might bias, or be perceived to bias, their work.

Contribution statement ICL conceived the objective of the study. ICL and LLL wrote and edited the manuscript. YN analysed the data. ICL, MAC, PCA, SEB, PAR and LLL contributed to the study design and interpretation of the data, and reviewed/edited the manuscript. AZ, FL and $\mathrm{CY}$ contributed to the interpretation of the data and reviewed/edited the manuscript. All authors provided final approval of the manuscript version published. ICL is the guarantor and accepts full responsibility for the work and/or the conduct of the study, had access to the data and controlled the decision to publish.

\section{References}

1. Wild S, Roglic G, Green A, Sicree R, King H (2004) Global prevalence of diabetes: estimates for the year 2000 and projections for 2030. Diabetes Care 27(5):1047-1053. https://doi.org/10.2337/ diacare.27.5.1047

2. Lipscombe LL, Hux JE (2007) Trends in diabetes prevalence, incidence, and mortality in Ontario, Canada 1995-2005: a populationbased study. Lancet 369(9563):750-756. https://doi.org/10.1016/ S0140-6736(07)60361-4
3. Cheng YJ, Imperatore G, Geiss LS et al (2013) Secular changes in the age-specific prevalence of diabetes among U.S. adults: 19882010. Diabetes Care 36(9):2690-2696. https://doi.org/10.2337/ dc12-2074

4. (1998) Intensive blood-glucose control with sulphonylureas or insulin compared with conventional treatment and risk of complications in patients with type 2 diabetes (UKPDS 33). UK Prospective Diabetes Study (UKPDS) Group. Lancet 352(9131): 837-853. https://doi.org/10.1128/AAMCol.14Aug.1998

5. Boucher BJ (1998) Inadequate vitamin D status: does it contribute to the disorders comprising syndrome ' $\mathrm{X}$ '? Br J Nutr 79(4):315-327

6. Group AC, Patel A, MacMahon S et al (2008) Intensive blood glucose control and vascular outcomes in patients with type 2 diabetes. N Engl J Med 358(24):2560-2572. https://doi.org/10. 1056/NEJMoa0802987

7. Budnitz DS, Lovegrove MC, Shehab N, Richards CL (2011) Emergency hospitalizations for adverse drug events in older Americans. N Engl J Med 365(21):2002-2012. https://doi.org/10. 1056/NEJMsa1 103053

8. Lipska KJ, Ross JS, Miao Y, Shah ND, Lee SJ, Steinman MA (2015) Potential overtreatment of diabetes mellitus in older adults with tight glycemic control. JAMA Intern Med 175(3):356-362. https://doi.org/10.1001/jamainternmed.2014.7345

9. Bolli G, de Feo P, Compagnucci P et al (1983) Abnormal glucose counterregulation in insulin-dependent diabetes mellitus. Interaction of anti-insulin antibodies and impaired glucagon and epinephrine secretion. Diabetes 32(2):134-141. https://doi.org/10. 2337/diab.32.2.134

10. Signorovitch JE, Macaulay D, Diener M et al (2013) Hypoglycaemia and accident risk in people with type 2 diabetes mellitus treated with non-insulin antidiabetes drugs. Diabetes Obes Metab 15(4):335-341. https://doi.org/10.1111/dom.12031

11. Goto A, Arah OA, Goto M, Terauchi Y, Noda M (2013) Severe hypoglycaemia and cardiovascular disease: systematic review and meta-analysis with bias analysis. BMJ 347:f4533. https://doi.org/ 10.1136/bmj.f4533

12. Khunti K, Davies M, Majeed A, Thorsted BL, Wolden ML, Paul SK (2015) Hypoglycemia and risk of cardiovascular disease and all-cause mortality in insulin-treated people with type 1 and type 2 diabetes: a cohort study. Diabetes Care 38(2):316-322. https://doi. org/10.2337/dc14-0920

13. Whitmer RA, Karter AJ, Yaffe K, Quesenberry CP Jr, Selby JV (2009) Hypoglycemic episodes and risk of dementia in older patients with type 2 diabetes mellitus. JAMA 301(15):1565-1572. https://doi.org/10.1001/jama.2009.460

14. Bonds DE, Miller ME, Bergenstal RM et al (2010) The association between symptomatic, severe hypoglycaemia and mortality in type 2 diabetes: retrospective epidemiological analysis of the ACCORD study. BMJ 340:b4909. https://doi.org/10.1136/bmj.b4909

15. Group AS, Gerstein HC, Miller ME et al (2011) Long-term effects of intensive glucose lowering on cardiovascular outcomes. N Engl $\mathrm{J}$ Med 364(9):818-828. https://doi.org/10.1056/NEJMoa1006524

16. Hayward RA, Reaven PD, Wiitala WL et al (2015) Follow-up of glycemic control and cardiovascular outcomes in type 2 diabetes. $\mathrm{N}$ Engl J Med 372(23):2197-2206. https://doi.org/10.1056/ NEJMoa1414266

17. Zoungas S, Chalmers J, Neal B et al (2014) Follow-up of bloodpressure lowering and glucose control in type 2 diabetes. $\mathrm{N}$ Engl $\mathrm{J}$ Med 371(15):1392-1406. https://doi.org/10.1056/ NEJMoa1407963

18. Lipska KJ, Krumholz H, Soones T, Lee SJ (2016) Polypharmacy in the aging patient: a review of glycemic control in older adults with type 2 diabetes. JAMA 315(10):1034-1045. https://doi.org/10. 1001/jama.2016.0299

19. Diabetes Canada Clinical Practice Guidelines Expert C, Meneilly GS, Knip A et al (2018) Diabetes in older people. Can J Diabetes 
42(Suppl 1):S283-S295. https://doi.org/10.1016/j.jcjd.2017.10. 021

20. LeRoith D, Biessels GJ, Braithwaite SS et al (2019) Treatment of diabetes in older adults: an Endocrine Society clinical practice guideline. J Clin Endocrinol Metab 104(5):1520-1574. https://doi. org/10.1210/jc.2019-00198

21. Arnold SV, Lipska KJ, Wang J, Seman L, Mehta SN, Kosiborod M (2018) Use of intensive glycemic management in older adults with diabetes mellitus. J Am Geriatr Soc 66(6):1190-1194. https://doi. org/10.1111/jgs. 15335

22. Tseng CL, Soroka O, Maney M, Aron DC, Pogach LM (2014) Assessing potential glycemic overtreatment in persons at hypoglycemic risk. JAMA Intern Med 174(2):259-268. https://doi.org/10. 1001/jamainternmed.2013.12963

23. Muller N, Khunti K, Kuss O et al (2017) Is there evidence of potential overtreatment of glycaemia in elderly people with type 2 diabetes? Data from the GUIDANCE study. Acta Diabetol 54(2): 209-214. https://doi.org/10.1007/s00592-016-0939-9

24. McCoy RG, Lipska KJ, Yao X, Ross JS, Montori VM, Shah ND (2016) Intensive treatment and severe hypoglycemia among adults with type 2 diabetes. JAMA Intern Med 176(7):969-978. https:// doi.org/10.1001/jamainternmed.2016.2275

25. Mahoney GK, Henk HJ, McCoy RG (2019) Severe hypoglycemia attributable to intensive glucose-lowering therapy among US adults with diabetes: population-based modeling study, 2011-2014. Mayo Clin Proc. https://doi.org/10.1016/j.mayocp.2019.02.028

26. Lipscombe LL, Gomes T, Levesque LE, Hux JE, Juurlink DN, Alter DA (2007) Thiazolidinediones and cardiovascular outcomes in older patients with diabetes. JAMA 298(22):2634-2643. https:// doi.org/10.1001/jama.298.22.2634

27. Hux JE, Ivis F, Flintoft V, Bica A (2002) Diabetes in Ontario: determination of prevalence and incidence using a validated administrative data algorithm. Diabetes Care 25(3):512-516. https://doi. org/10.2337/diacare.25.3.512

28. Khan H, Lasker SS, Chowdhury TA (2011) Exploring reasons for very poor glycaemic control in patients with type 2 diabetes. Prim Care Diabetes 5(4):251-255. https://doi.org/10.1016/j.pcd.2011.07.001

29. Reid RJ, Roos NP, MacWilliam L, Frohlich N, Black C (2002) Assessing population health care need using a claims-based ACG morbidity measure: a validation analysis in the Province of Manitoba. Health Serv Res 37(5):1345-1364. https://doi.org/10. 1111/1475-6773.01029

30. King N, King M (2014) The Ontario cancer registry moves to the 21st century. Cancer Care Ontario, Toronto

31. Jaakkimainen RL, Bronskill SE, Tierney MC et al (2016) Identification of physician-diagnosed Alzheimer's disease and related dementias in population-based administrative data: a validation study using family physicians' electronic medical records. J Alzheimers Dis 54(1):337349. https://doi.org/10.3233/JAD-160105

32. Schultz SE, Rothwell DM, Chen Z, Tu K (2013) Identifying cases of congestive heart failure from administrative data: a validation study using primary care patient records. Chronic Dis Inj Can 33(3):160-166

33. Tam DY, Dharma C, Rocha R et al (2020) Long-term survival after surgical or percutaneous revascularization in patients with diabetes and multivessel coronary disease. J Am Coll Cardiol 76(10):1153-1164

34. Singh SM, Abdel-Qadir H, Pang A et al (2020) Population trends in all-cause mortality and cause specific-death with incident atrial fibrillation. J Am Heart Assoc 9(19):e016810. https://doi.org/10. 1016/j.compbiomed.2020.104185

35. Yu AY, Austin PC, Rashid M et al (2020) Deriving a passive surveillance stroke severity indicator from routinely collected administrative data: the PaSSV Indicator. Circ Cardiovasc Qual Outcomes 13(2): 0006269

36. Austin PC (2011) An introduction to propensity score methods for reducing the effects of confounding in observational studies. Multivar Behav Res 46(3):399-424. https://doi.org/10.1080/ 00273171.2011 .568786

37. Austin PC, Stuart EA (2015) Moving towards best practice when using inverse probability of treatment weighting (IPTW) using the propensity score to estimate causal treatment effects in observational studies. Stat Med 34(28):3661-3679. https://doi.org/10.1002/sim.6607

38. Duckworth W, Abraira C, Moritz T et al (2009) Glucose control and vascular complications in veterans with type 2 diabetes. $\mathrm{N}$ Engl J Med 360(2):129-139. https://doi.org/10.1056/NEJMoa0808431

39. Mitchell AP, Harrison MR, Walker MS, George DJ, Abernethy AP, Hirsch BR (2015) Clinical trial participants with metastatic renal cell carcinoma differ from patients treated in real-world practice. J Oncol Pract 11(6):491-497. https://doi.org/10.1200/JOP.2015.004929

40. Gangji AS, Cukierman T, Gerstein HC, Goldsmith CH, Clase CM (2007) A systematic review and meta-analysis of hypoglycemia and cardiovascular events: a comparison of glyburide with other secretagogues and with insulin. Diabetes Care 30(2):389-394. https:// doi.org/10.2337/dc06-1789

41. Hubbard R, Andrew M, Fallah N, Rockwood K (2010) Comparison of the prognostic importance of diagnosed diabetes, co-morbidity and frailty in older people. Diabet Med 27(5):603-606. https://doi. org/10.1111/j.1464-5491.2010.02977.x

42. Hambling CE, Seidu SI, Davies MJ, Khunti K (2017) Older people with type 2 diabetes, including those with chronic kidney disease or dementia, are commonly overtreated with sulfonylurea or insulin therapies. Diabet Med 34(9):1219-1227. https://doi.org/10.1111/ dme. 13380

43. American Diabetes Association (2019) 12. Older adults: standards of medical care in diabetes - 2019. Diabetes Care 42(Suppl 1): S139-S147. https://doi.org/10.2337/dc19-S012

44. Canadian Diabetes Association Clinical Practice Guidelines Expert Committee; Meneilly GS, Knip A, Tessier D (2013) Diabetes in the elderly. Can J Diabetes 37:184-190

45. Yu CH, Gall Casey C, Ke C, Lebovic G, Straus SE (2019) Process evaluation of the Diabetes Canada guidelines dissemination strategy using the Reach Effectiveness Adoption Implementation Maintenance (RE-AIM) framework. Can J Diabetes 43(4):263270.e9. https://doi.org/10.1016/j.jcjd.2018.08.189

46. Yu CH, Lillie E, Mascarenhas-Johnson A, Gall Casey C, Straus SE (2018) Impact of the Canadian Diabetes Association guideline dissemination strategy on clinician knowledge and behaviour change outcomes. Diabetes Res Clin Pract 140:314-323. https:// doi.org/10.1016/j.diabres.2018.02.041

47. Markovitz AA, Hofer TP, Froehlich W et al (2018) An examination of deintensification recommendations in clinical practice guidelines: stepping up or scaling back? JAMA Intern Med 178(3): 414-416. https://doi.org/10.1001/jamainternmed.2017.7198

48. Caverly TJ, Fagerlin A, Zikmund-Fisher BJ et al (2015) Appropriate prescribing for patients with diabetes at high risk for hypoglycemia: national survey of veterans affairs health care professionals. JAMA Intern Med 175(12):1994-1996. https://doi. org/10.1001/jamainternmed.2015.5950

49. Godolphin W (2009) Shared decision-making. Healthc Q 12 Spec No Patient: e186-190

Publisher's note Springer Nature remains neutral with regard to jurisdictional claims in published maps and institutional affiliations. 